\title{
PENENTUAN PROVIDER INTERNET TEPAT DI LINGKUNGAN PEMUKIMAN PADAT PENDUDUK MENGGUNAKAN ANALYTICAL HIERARCHY PROCESS
}

\author{
Guna Yanti Kemala Sari Siregar, Ika Arthalia Wulandari \\ Program Studi IImu Komputer, Fakultas IImu Komputer \\ Universitas Muhammadiyah Metro \\ Jl. Gatot Subroto, Yosodadi, Metro Timur, Kota Metro
}

\begin{abstract}
Abstrak - Para Perusahaan Provider Penyedia jasa Internet bersaing harga dalam menawarkan berbagai jeni layanan paket internet. Dan dengan promosi yang sangat banyak dan marak sekali membuat konsumen sangat kesulitan menentukan pilihan yang sesuai dengan kebutuhan dari masing-masing konsumen. Sebagai bentuk kepedulian tersebut maka saya membuat sebuah Konsep Sistem Pendukung keputusan yang dapat diterapkan di lingkungan area pemukiman padat penduduk. Salah satu metode yang relevan serta memiliki perhitungan nilai konsistensi dalam menentukan tingkat prioritas kriteria adalah metode Analytical Hierarchy Process (AHP). Penelitian ini bertujuan untuk menentukan provider internet yang tepat sesuai kebutuhan di area pemukiman padat penduduk. Hasil keputusan yang diperoleh nantinya dapat memberikan minat positif dengan berbagai kriteria yang dipertimbangkan kepada para calon konsumen. Hasil penelitian menunjukkan nilai rasio konsistensi 0.0794 yang berarti kurang dari nilai rasio konsistensi yang digunakan dalam metode AHP yaitu 0.1, sehingga hasil perhitungan tersebut valid, dan dapat digunakan. Hasil akhir dari aplikasi ini memberikan dukungan keputusan bahwa IndiHome merupakan provider paling ideal untuk digunakan pada jaringan nirkabel di area lingkungan area rumah dengan nilai $(0,218531)$ diikuti dengan First Media $(0,192079)$, CBN $(0,166819)$, Biznet Home $(0,157438)$, Myrepublic $(0,147877)$ dan MNC Play $(0,117257)$. Hasil tersebut diperoleh dari perhitungan prioritas kriteria dan alternatif menggunakan metode AHP.
\end{abstract}

Kata Kunci: Analytical Hierarchy Process (AHP), Provider Internet, Sistem Pendukung Keputusan

Abstract - Internet service providers are competitively priced in offering various types of internet package services. And with so many promotions and so many people making it very difficult for consumers to make choices that suit the needs of each consumer. As a form of this concern, I created a decision support system concept that can be applied in densely populated residential areas. One method that is relevant and has the calculation of the value of consistency in determining the priority level of the criteria is the Analytical Hierarchy Process (AHP) method. This study aims to determine the right internet provider according to the needs in densely populated residential areas. The results obtained later can provide positive interest with various criteria considered to potential consumers. The results showed that the value of the consistency ratio was 0.0794, which means less than the value of the consistency ratio used in the AHP method, which is 0.1 , so the results of the calculation are valid and can be used. The final result of this 
application provides decision support that IndiHome is the most ideal provider for use in wireless networks in the home area with a value of (0.218531) followed by First Media (0.192079), CBN (0.166819), Biznet Home (0.157438), My Republic (0.147877) and MNC Play (0.117257). These results were obtained from the calculation of the priority criteria and alternatives using the $A H P$ method.

Keywords : Analytical Hierarchy Process (AHP), Internet Provider, Decision Support System

\section{PENDAHULUAN}

Jumlah pengguna Internet di Indonesia saat ini sangat berkembang yang mengakibatkan banyak Internet service provider bersaing dalam menawarkan paket internet yang menarik untuk semua konsumen, agar produk provider laku keras dan bersaing di masyarakat dengan cepat. Hal ini sesuai dengan prediksi yang menunjukkan bahwa indonesia akan menduduki peringkat lima dunia dalam hal pengguna internet. Berbagai pilihan penyedia jasa internet, tidak jarang membuat calon konsumen kesulitan untuk menentukan layanan paket internet yang sesuai dengan kebutuhan. Hal ini disebabkan konsumen perlu mempertimbangkan berbagai kriteria sebelum memutuskan memilih penyedia jasa internet yang akan digunakan. Sejalan dengan itu, konsumen dapat menggunakan konsep sistem pendukung keputusan dengan menggunakan sistem pelayanan yang terkomputerisasi dan nantinya digunakan dalam jaringan nirkabel di area lingkungan padat penduduk. Sistem Pendukung Keputusan (SPK) merupakan sistem yang dapat memberikan pemecahan masalah, melakukan komunikasi untuk pemecahan masalah tertentu dengan terstruktur maupun tidak terstruktur. SPK didesain untuk dapat digunakan dan dioperasikan dengan mudah oleh orang yang hanya memiliki kemampuan dasar pengoperasian komputer. Sistem Pendukung Keputusan (SPK) dibuat dengan menerapkan adaptasi kompetensi yang tinggi sehingga dapat dijadikan sebagai alternatif dalam pengambilan sebuah keputusan. Sistem Pendukung Keputusan (SPK) terdiri atas dua kata kunci, yaitu sistem informasi dan keputusan. Sistem informasi merupakan serangkaian prosedur formal dengan tahapan dimana data dikelompokkan, diproses sehingga menghasilkan informasi yang selanjutnya diberikan kepada pengguna. Keputusan adalah serangkaian kegiatan untuk memilih suatu tindakan dalam memecahkan masalah. Tindakan memilih dari alternatif yang dihadapi yang didasarkan pada fakta dan dilakukan melalui pendekatan sistematis yang dapat memberikan solusi terbaik yang dilakukan oleh manajer disebut pengambilan keputusan. Salah satu sistem pendukung keputusan yang relevan serta memiliki penghitungan nilai konsistensi dalam menentukan tingkat prioritas kriteria dan alternatif adalah metode Analytical Hierarchy Process (AHP). Konsep dari AHP adalah mengubah nilai-nilai kualitatif menjadi nilainilai kuantitatif. Metode ini juga menggabungkan kekuatan dari perasaan dan logika yang bersangkutan pada berbagai persoalan, lalu mensintesis berbagai pertimbangan yang beragam menjadi hasil yang cocok dengan perkiraan secara intuitif sebagaimana yang dipresentasikan pada pertimbangan yang telah dibuat. Metode AHP awalnya dikembangkan oleh Thomas L. Saaty, 
dengan kegunaan utamanya adalah memecahkan masalah dan pengambilan keputusan di lingkungan multikriteria. AHP menentukan bobot prioritas sebagai alternatif dengan mengatur tujuan, kriteria, dan subkriteria dalam struktur hierarki. Penelitian terkait AHP telah banyak dilakukan. Umar, Fadlil, dan Yuminah membahas penilaian kompetensi soft skill karyawan dengan menerapkan metode AHP. Penelitian tersebut menggunakan empat kriteria yaitu kemampuan komunikasi, kemampuan bekerja sama, kejujuran, dan kemampuan interpersonal. Hasil penelitian menunjukkan nilai rasio konsistensi 0.053 dan prioritas yang didapat adalah Komunikasi 48\%, Kerjasama 27\%, Kejujuran $16 \%$, dan interpersonal $10 \%$.Musthafa dan Mubarok menggunakan metode AHP sebagai alat bantu dalam menentukan mahasiswa berprestasi. Metode tersebut relevan serta memiliki penghitungan nilai konsistensi dalam menentukan tingkat prioritas kriteria. Hasil dari penelitian ini merupakan sistem yang dapat memberikan rekomendasi alternatif penerima mahasiswa berprestasi dengan nilai indeks konsisten sebesar 0,06, sehingga hierarki yang dibentuk dapat diterima . Rizaldi menerapkan metode AHP untuk menentukan operator kartu seluler terbaik yang nantinya digunakan untuk menjalin komunikasi antar pengguna, kriteria yang dipertimbangkan berupa harga, tarif, promo dan masa aktif.

\section{KAJIAN PUSTAKA DAN PENGEMBANGAN HIPOTESIS}

Kajian Pustaka pada penelitian ini di referensi dari penelitian sebelumnya yaitu :

1. Sistem Pendukung Keputusan Untuk menyeleksi penerima dana bantuan siswa miskin menggunakan Metode Simple Additive Weighting (SAW). Yang dilakukan oleh : Guna Yanti Kemala Sari Siregar, Pada Jurnal Expert Universitas Bandar Lampung Volume 8 No 2 Tahun 2018.

2. Metode Simple Additive Weighting (SAW) sebagai sistem pendukung keputusan Penerima Beasiswa Murid Berprestasi. Yang dilakukan oleh Rahmat Hidayat, Pada Sinkron Jurnal Penelitian Teknik Informatika Volume 2 No 2, Oktober 2017

\section{METODE PENELITIAN}

Metode yang digunakan diantaranya yaitu : Dalam memperoleh data untuk menyusun tugas akhir ini, penulis menggunakan metode yaitu :

1. Studi Lapangan

Studi Lapangan adalah pengumpulan secara langsung mempelajari sebuah sistem yang berkaitan dengan masalah yang sedang yang sedang dihadapi. Adapun studi lapangan yang penulis lakukan dengan teknik:

\section{Pengamatan (Observation)}

Yaitu dengan cara melakukan penelitian secara langsung pada Dinas Komunikasi dan Informatika Kota Metro, sehingga penulis

mengetahui alur sistem kerja yang berjalan saat ini.

1. Wawancara (Interview)

Wawancara yaitu mengumpulkan datadata dengan cara melakukan tanya jawab atau tatap muka secara langsung dengan pegawai yang bekerja di bagian Kasubag di lingkungan penelitian.

\section{Dokumentasi (Documentation)}

Penulis membutuhkan tambahan data sebagai pelengkap tugas akhir dengan 
cara mengumpulkan dokumentasi yang terkait.

3. Studi Pustaka

Studi Pustaka merupakan pengumpulan data dengan cara membaca buku-buku, dan mempelajari sistem kerja yang berkaitan dengan penelitian. kesimpulan bahwa nilai sudah memenuhi syarat konsistensi atau tidak. Hasil perbandingan tersebut dimasukan pada sel yang bersesuaian dengan elemen yang dibandingkan seperti yang ditampilkan pada Tabel 2.

\section{PEMBAHASAN}

\section{Penentuan Prioritas Kriteria}

Setelah mendapatkan data kriteria dari kuesioner, selanjutnya menentukan prioritas kriteria. Pertama mendefinisikan nilai perbandingan dari masing-masing elemen, lalu normalisasi nilai perbandingan, pencarian priority vector, perhitungan principal eigenvector ( $\lambda$ maks), perhitungan consistency index, dan yang terakhir perhitungan consistency ratio untuk mendapat

Tabel 2. Tabel Matriks Perbandingan Berpasangan Kriteria

\begin{tabular}{lccccc}
\hline \multicolumn{1}{c}{ Kriteria } & $\begin{array}{c}\text { Harga } \\
\text { Bulanan }\end{array}$ & $\begin{array}{c}\text { Area yang } \\
\text { didukung }\end{array}$ & $\begin{array}{c}\text { Kecepatan } \\
\text { Internet }\end{array}$ & $\begin{array}{c}\text { Ketersediaan } \\
\text { TV Kabel }\end{array}$ & $\begin{array}{c}\text { Biaya } \\
\text { Registrasi }\end{array}$ \\
\hline Harga Bulanan & 1 & 1,66834 & 1,82552 & 4,72266 & 2,76663 \\
Area yang didukung & 0,5994 & 1 & 2,73227 & 4,17233 & 3,10575 \\
Kecepatan Internet & 0,54779 & 0,366 & 1 & 5,13105 & 3,32902 \\
Ketersediaan TV Kabel & 0,21175 & 0,23967 & 0,19489 & 1 & 1,38985 \\
Biaya Registrasi & 0,36145 & 0,32198 & 0,30039 & 0,7195 & 1 \\
Jumlah & 2,72038 & 3,59599 & 6,05307 & 15,74554 & 11,59125 \\
\hline
\end{tabular}

Selanjutnya menormalkan data yaitu dengan cara membagi setiap nilai elemen matriks perbandingan berpasangan dari kriteria dengan jumlah setiap kolom jumlah dari kriteria. Hasil normalisasi

kriteria tersebut dimasukkan pada sel yang bersesuaian dengan elemen normalisasi seperti diperlihatkan pada Tabel 3.

Tabel 3. Tabel Matriks Normalisasi Perbandingan Kriteria

\begin{tabular}{ccccccc}
\hline Kriteria & Harga & Area & Kecepatan & TV Kabel & Registrasi & Jumlah \\
\hline Harga & 0,3676 & 0,46394 & 0,30159 & 0,29994 & 0,23868 & 1,67174 \\
Area & 0,22034 & 0,27809 & 0,45139 & 0,26498 & 0,26794 & 1,48273 \\
Kecepatan & 0,20136 & 0,10178 & 0,16521 & 0,32587 & 0,2872 & 1,08142 \\
TV Kabel & 0,07784 & 0,06665 & 0,0322 & 0,06351 & 0,11991 & 0,3601 \\
Registrasi & 0,13287 & 0,08954 & 0,04963 & 0,0457 & 0,08627 & 0,404 \\
\hline
\end{tabular}




\section{Jurnal IImu Komputer dan Informatika Vol 2 № 2 p-ISSN: 2776-7418 e-ISSN: 2746-508X}

Setelah melakukan normalisasi, selanjutnya melakukan perhitungan nilai priority vector kriteria dengan cara menghitung rata setiap baris hasil normalisasi. Nilai priority vector kriteria ini merupakan bobot dari masing-masing kriteria yang dijabarkan pada Tabel 4

Tabel 4. Tabel Priority Vektor Kriteria

\begin{tabular}{c} 
Priority Vektor Kriteria \\
\hline 0,33435 \\
0,29655 \\
0,21628 \\
0,07202 \\
0,0808 \\
\hline
\end{tabular}

Principal eigenvector ( $\lambda$ maks) diperoleh dengan menjumlahkan hasil perkalian jumlah kolom perbandingan kriteria dengan priority vector sesuai terlampir pada Tabel 2 dan 4. Principal eigenvector ( $\lambda$ maks) dihitung menggunakan Persamaan (8).

$(\lambda$ maks $)=(\mathrm{JHxPvH})+(\mathrm{JAxPvA})+\ldots$ (JRxPvR)

Dimana: $\mathrm{JH}=$ Jumlah Harga

$\mathrm{PvH}=$ Priority Vector Harga

$\mathrm{PvA}=$ Priority Vector Area

$\mathrm{PvR}=$ Priority Vector Registrasi $\lambda$ maks $=$ Principal eigenvector

Berdasarkan persamaan (8) didapat:

$(\lambda$ maks $)=(2,72038 \times 0,33435)+$

$(3,59599$

$\times 0,29655)+(6,05307 \times 0,21628)+$

$(15,74554 \times 0,07202)+(11,59125 \times$

$0,0808)=5,35569$

Untuk mengetahui tingkat konsistensi perbandingan yang dilakukan, maka dihitung nilai Consistency Index $(\mathrm{Cl})$ dan Consistency Ratio (CR). Indeks konsistensi dapat diperoleh dengan rumus pada Persamaan (9).

$\mathrm{Cl}=(\lambda$ maks $-\mathrm{n}) /(\mathrm{n}-1)(9)$

Dimana $: \mathrm{Cl}=$ Consistency Index

$\lambda$ maks $\quad=$ Principal eigenvector

$\mathrm{n} \quad=$ banyaknya kriteria

Berikut adalah hasil dari perhitungan consistency index berdasarkan persamaan (9),

$\mathrm{Cl}=(5,35569-5) /(5-1)=0,35569 / 4=$ 0,08892

Batas toleransi inkonsistensi diukur menggunakan Consistency Ratio (CR). Bila nilai CR lebih kecil dari $10 \%(0,10)$ syarat konsistensi perbandingan masih dapat diterima, namun jika nilai lebih besar dari $(0,10)$ maka harus dilakukan perbandingan penilaian ulang. Indeks random konsistensi diperlihatkan pada Tabel 5.

Tabel 5. Tabel Indeks Random

\begin{tabular}{|c|c|c|c|c|c|c|c|c|c|c|c|c|c|c|c|}
\hline $\mathrm{N}$ & 1 & 2 & 3 & 4 & 5 & 6 & 7 & 8 & 9 & 10 & 11 & 12 & 13 & 14 & 15 \\
\hline $\mathrm{RI}$ & 0 & 0 & 0,58 & 0,9 & 1,12 & 1,24 & 1,32 & 1,41 & 1,45 & 1,49 & 1,51 & 1,54 & 1,56 & 1,57 & 1,59 \\
\hline
\end{tabular}

Nilai RI didapat sesuai dengan jumlah ordo matriks atau jumlah kriteria yang digunakan. Penelitian ini menggunakan 5 ordo sehingga nilai $\mathrm{RI}$ yang digunakan 1,12 sesuai terlampir pada Tabel

1. Berikut adalah hasil dari perhitungan 


\section{Jurnal IImu Komputer dan Informatika Vol 2 № 2 \\ p-ISSN: 2776-7418 e-ISSN: 2746-508X}

consistency index.

$\mathrm{CR}=\mathrm{Cl} / \mathrm{RI}=0,08892 / 1,12=0,0794$

* $(100)=7.94 \%$
Jadi, dapat disimpulkan nilai prioritas kriteria yang diperlihatkan pada Tabel 4 dan dikarenakan nilai konsistensi kurang dari 0,1 maka syarat konsistensi masih bisa diterima.

\section{Penentuan Prioritas Alternatif}

Penentuan prioritas alternatif dilakukan dengan cara melakukan perbandingan alternatif sebanyak 5 kali untuk tiap kriteria dan dengan perhitungan yang sama dengan penentuan prioritas kriteria dan dengan hasil pembobotan yang konsisten. Untuk menentukan nilai perbandingan alternatif, dibutuhkan informasi layanan paket internet yang sesuai dengan kelasnya. Untuk mendapatkan nilai preferensi bobot kepentingan dari kriteria-kriteria yang digunakan, yang datanya didapat dari nilai individu sesuai dengan laman resmi penyedia jasa internet untuk dianalisa, dianalogikan dan disesuaikan dengan keadaan tempat tinggal pengambil keputusan, berikut data perbandingan seluruh alternatif berdasarkan kriteria yang diperlihatkan pada Tabel 6.

Tabel 6. Nilai Perbandingan Individu Alternatif

\begin{tabular}{lccccc}
\hline \multicolumn{1}{c}{$\begin{array}{c}\text { Perbandingan } \\
\text { Alternatif }\end{array}$} & Harga & Area & Kecepatan & TV Kabel & Registrasi \\
\hline FirstMedia-MyRepublic & 2 & 2 & 0,33 & 5 & 3 \\
FirstMedia-Biznet Home & 3 & 2 & 0,16 & 3 & 3 \\
FirstMedia-MNC Play & 2 & 2 & 0,5 & 3 & 1 \\
FirstMedia-Indihome & 2 & 0,5 & 0,5 & 2 & 0,5 \\
FirstMedia-CBN & 0,5 & 4 & 0,33 & 5 & 3 \\
MyRepublic-Biznet & 3 & 1 & 0,5 & 0,25 & 1 \\
Home & & & & & \\
MyRepublic-MNC Play & 2 & 1 & 2 & 0,33 & 0,33 \\
MyRepublic-Indihome & 2 & 0,33 & 2 & 0,2 & 0,2 \\
MyRepublic-CBN & 0,5 & 3 & 2 & 0,5 & 1 \\
Biznet Home-MNC Play & 0,33 & 1 & 4 & 2 & 0,33 \\
Biznet Home-Indihome & 0,33 & 0,33 & 4 & 0,5 & 0,2 \\
Biznet Home-CBN & 0,25 & 3 & 3 & 3 & 1 \\
MNC Play-Indihome & 0,5 & 0,33 & 1 & 0,33 & 0,5 \\
MNC Play-CBN & 0,33 & 3 & 0,5 & 2 & 3 \\
Indihome-CBN & 0,33 & 5 & 0,5 & 4 & 5 \\
\hline
\end{tabular}


Hasil perbandingan tersebut dimasukkan pada sel yang bersesuaian dengan elemen yang disbanding- kan, yang salah satunya yaitu alternatif berdasarkan harga bulanan diperlihatkan pada Tabel 7.

Tabel 7. Tabel Matriks Perbandingan Berpasangan Alternatif Harga Bulanan

\begin{tabular}{|c|c|c|c|c|c|c|}
\hline Alternatif & $\begin{array}{c}\text { First } \\
\text { Media }\end{array}$ & MyRepublic & $\begin{array}{l}\text { Biznet } \\
\text { Home }\end{array}$ & $\begin{array}{l}\text { MNC } \\
\text { Play }\end{array}$ & $\begin{array}{c}\text { Indi } \\
\text { Home }\end{array}$ & CBN \\
\hline First Media & 1 & 2 & 3 & 2 & 2 & 0,5 \\
\hline MyRepublic & 0,5 & 1 & 3 & 2 & 2 & 0,5 \\
\hline Biznet Home & 0,33 & 0,33 & 1 & 0,33 & 0,33 & 0,25 \\
\hline MNC Play & 0,5 & 0,5 & 3 & 1 & 0,5 & 0,33 \\
\hline Indi Home & 0,5 & 0,5 & 3 & 2 & 1 & 0,33 \\
\hline CBN & 2 & 2 & 4 & 3 & 3 & 1 \\
\hline Jumlah & 4,83333 & 6,33333 & $\begin{array}{c}17,000 \\
01 \\
\end{array}$ & 10,33334 & 8,83334 & 2,91667 \\
\hline
\end{tabular}

Selanjutnya menormalkan data dan kemudian mencari nilai prioritas dan uji konsistensi. Selengkapnya untuk alternatif harga bulanan diperlihatkan pada Tabel 8.Nilai prioritas alternatif area yang didukung diperlihatkan pada
Tabel 9. Nilai prioritas alternatif kecepatan internet diperlihatkan pada Tabel 10. Nilai prioritas alternatif ketersediaan TV kabel diperlihatkan pada Tabel 11. Nilai prioritas alternatif biaya registrasi diperlihatkan pada Tabel 12.

Tabel 8. Tabel Prioritas dan Konsistensi Alternatif Harga Bulanan

\begin{tabular}{ccccccccc}
\hline Perhitungan & A1 & A2 & A3 & A4 & A5 & A6 & Jumlah & Priority Vector \\
\hline A1 & 0,206 & 0,315 & 0,176 & 0,193 & 0,226 & 0,171 & 1,290 & 0,215 \\
A2 & 0,103 & 0,157 & 0,176 & 0,193 & 0,226 & 0,171 & 1,029 & 0,171 \\
A3 & 0,068 & 0,052 & 0,058 & 0,032 & 0,037 & 0,085 & 0,336 & 0,056 \\
A4 & 0,103 & 0,078 & 0,176 & 0,096 & 0,056 & 0,114 & 0,626 & 0,104 \\
A5 & 0,103 & 0,078 & 0,176 & 0,193 & 0,113 & 0,114 & 0,779 & 0,129 \\
A6 & 0,413 & 0,315 & 0,235 & 0,290 & 0,339 & 0,342 & 1,937 & 0,322 \\
Principal eigenvector & $(\lambda$ maks) & & & & & & 6,247 \\
\multicolumn{2}{l}{$\begin{array}{l}\text { Consistency Index } \\
\text { Consistency Ratio }\end{array}$} & & & & & & & 0,049 \\
\hline
\end{tabular}

Tabel 9. Tabel Prioritas dan Konsistensi Alternatif Area yang didukung

\begin{tabular}{ccccccccc}
\hline Perhitungan & A1 & A2 & A3 & A4 & A5 & A6 & Jumlah & Priority Vector \\
\hline A1 & 0,210 & 0,24 & 0,24 & 0,24 & 0,185 & 0,210 & 1,326 & 0,221 \\
A2 & 0,105 & 0,12 & 0,12 & 0,12 & 0,123 & 0,157 & 0,746 & 0,124 \\
A3 & 0,105 & 0,12 & 0,12 & 0,12 & 0,123 & 0,157 & 0,746 & 0,124 \\
A4 & 0,105 & 0,12 & 0,12 & 0,12 & 0,123 & 0,157 & 0,746 & 0,124 \\
A5 & 0,421 & 0,36 & 0,36 & 0,36 & 0,370 & 0,263 & 2,134 & 0,355 \\
A6 & 0,052 & 0,04 & 0,04 & 0,04 & 0,074 & 0,052 & 0,299 & 0,049
\end{tabular}




\begin{tabular}{|c|c|c|c|c|c|c|c|c|}
\hline \multirow{2}{*}{$\begin{array}{l}\text { Principal eigenvector } \\
\text { Consistency Index }\end{array}$} & \multicolumn{2}{|r|}{$(\lambda$ maks $)$} & & & & & & 6,069 \\
\hline & & & & & & & & 0,013 \\
\hline Consistency Ratio & & & & & & & & $1,12 \%$ \\
\hline \multicolumn{9}{|c|}{ Tabel 10. Tabel Prioritas dan Konsistensi Alternatif Kecepatan Internet } \\
\hline Perhitungan & A1 & A2 & A3 & A4 & A5 & A6 & Jumlah & Priority Vector \\
\hline $\mathrm{A} 1$ & 0,058 & 0,068 & 0,066 & 0,047 & 0,047 & 0,045 & 0,335 & 0,055 \\
\hline $\mathrm{A} 2$ & 0,176 & 0,206 & 0,2 & 0,190 & 0,190 & 0,272 & 1,237 & 0,206 \\
\hline A3 & 0,352 & 0,413 & 0,4 & 0,380 & 0,380 & 0,409 & 2,337 & 0,389 \\
\hline A4 & 0,117 & 0,103 & 0,1 & 0,095 & 0,095 & 0,068 & 0,579 & 0,096 \\
\hline A5 & 0,117 & 0,103 & 0,1 & 0,095 & 0,095 & 0,068 & 0,579 & 0,096 \\
\hline A6 & 0,176 & 0,103 & 0,133 & 0,190 & $P, 190$ & 0,136 & 0,930 & 0,155 \\
\hline \multicolumn{2}{|l|}{ Principal eigenvector } & $(\lambda$ maks $)$ & & & & & & 6,086 \\
\hline \multicolumn{3}{|l|}{ Consistency Index } & & & & & & 0,017 \\
\hline \multicolumn{3}{|l|}{ Consistency Ratio } & & & & & & $1,4 \%$ \\
\hline
\end{tabular}

tabel 11. Tabel Prioritas dan Konsistensi Alternatif Ketersediaan TV Kabel

\begin{tabular}{ccccccccc}
\hline Perhitungan & A1 & A2 & A3 & A4 & A5 & A6 & Jumlah & Priority Vector \\
\hline A1 & 0,389 & 0,25 & 0,423 & 0,305 & 0,466 & 0,322 & 2,157 & 0,359 \\
A2 & 0,077 & 0,05 & 0,035 & 0,033 & 0,046 & 0,032 & 0,276 & 0,046 \\
A3 & 0,129 & 0,2 & 0,141 & 0,203 & 0,116 & 0,193 & 0,984 & 0,164 \\
A4 & 0,129 & 0,15 & 0,070 & 0,101 & 0,077 & 0,129 & 0,659 & 0,109 \\
A5 & 0,194 & 0,25 & 0,282 & 0,305 & 0,233 & 0,258 & 1,523 & 0,253 \\
A6 & 0,077 & 0,1 & 0,047 & 0,050 & 0,058 & 0,064 & 0,398 & 0,066 \\
Principal eigenvector $(\lambda$ maks) & & & & & & 6,203 \\
Consistency Index & & & & & & & 0,040 \\
\multicolumn{2}{l}{ Consistency Ratio } & & & & & & & 3,28 \\
\hline
\end{tabular}

Tabel 12. Tabel Prioritas dan Konsistensi Alternatif Biaya Registrasi

\begin{tabular}{ccccccccc}
\hline Perhitungan & A1 & A2 & A3 & A4 & A5 & A6 & Jumlah & Priority Vector \\
\hline A1 & 0,2 & 0,214 & 0,214 & 0,2 & 0,192 & 0,214 & 1,235 & 0,205 \\
A2 & 0,066 & 0,071 & 0,071 & 0,066 & 0,076 & 0,071 & 0,424 & 0,070 \\
A3 & 0,066 & 0,071 & 0,071 & 0,066 & 0,076 & 0,071 & 0,424 & 0,070 \\
A4 & 0,2 & 0,214 & 0,214 & 0,2 & 0,192 & 0,214 & 1,235 & 0,205 \\
A5 & 0,4 & 0,357 & 0,357 & 0,4 & 0,384 & 0,357 & 2,256 & 0,376 \\
A6 & 0,066 & 0,071 & 0,071 & 0,066 & 0,076 & 0,071 & 0,424 & 0,070 \\
\multicolumn{2}{l}{$\begin{array}{c}\text { Principal eigenvector } \\
\text { Consistency Index }\end{array}$} & $(\lambda$ maks) & & & & & & 6,008 \\
\multicolumn{2}{l}{ Consistency Ratio } & & & & & & & 0,001 \\
\hline
\end{tabular}

\section{Hasil Akhir Peringkat}

Langkah selanjutnya adalah mencari kesimpulan dari nilai akhir masing-masing alternatif dengan cara melakukan perkalian matriks antara nilai priority vector alternatif dengan nilai priority vector kriteria. Hasil perkalian matriks dan nilai akhir alternatif diperlihatkan pada Tabel 1 
Tabel 13. Tabel Hasil Perhitungan Peringkat

\begin{tabular}{lrrcrcrc}
\hline \multicolumn{1}{c}{$\begin{array}{c}\text { Overall Composite } \\
\text { Height }\end{array}$} & $\begin{array}{c}\text { Priority } \\
\text { Vektor } \\
\text { Kriteria }\end{array}$ & $\begin{array}{c}\text { First } \\
\text { Media }\end{array}$ & $\begin{array}{c}\text { My } \\
\text { Republic }\end{array}$ & $\begin{array}{c}\text { Biznet } \\
\text { Home }\end{array}$ & $\begin{array}{c}\text { MNC } \\
\text { Play }\end{array}$ & $\begin{array}{c}\text { Indi } \\
\text { Home }\end{array}$ & CBN \\
\hline Harga Bulanan & 0,324 & 0,215 & 0,171 & 0,056 & 0,104 & 0,129 & 0,322 \\
Area yang didukung & 0,297 & 0,221 & 0,124 & 0,124 & 0,124 & 0,355 & 0,049 \\
Kecepatan Internet & 0,224 & 0,055 & 0,206 & 0,389 & 0,096 & 0,096 & 0,115 \\
Ketersediaan TV Kabel & 0,070 & 0,359 & 0,046 & 0,164 & 0,109 & 0,253 & 0,066 \\
Biaya Registrasi & 0,082 & 0,205 & 0,070 & 0,070 & 0,205 & 0,376 & 0,070 \\
\hline Total & & 0,190 & 0,148 & 0,160 & 0,117 & 0,218 & 0,165 \\
\hline
\end{tabular}

Hasil perhitungan total diperoleh dengan menjumlahkan hasil perkalian priority vector riteria dengan priority vector alternatif dengan rumus pada Persamaan (10). NT = $($ PvHxPva1H $)+($ PvAxPva1A $)+$

$$
\text { ... (PvRxPva1R) }
$$

Dimana:

NT $=$ Nilai Total

$\mathrm{PvH}=$ Priority Vector Harga

Pva1H = Priority Vector Alternatif Harga
PvA = Priority Vector Area

Pva1A = Priority Vector Alternatif Area

$\mathrm{PvR}=$ Priority Vector Registrasi

Pva1 $\mathrm{R}=$ Priority Vector Alternatif Registrasi

Hasil peringkat diperlihatkan pada Tabel 14 .

Tabel 14. Tabel Hasil Peringkat

\begin{tabular}{|c|c|c|}
\hline Peringkat & Alternatif & Nilai \\
\hline 1. & Indi Home & 0,218531 \\
\hline 2. & First Media & 0,192079 \\
\hline 3. & CBN & 0,166819 \\
\hline 4. & Biznet Home & 0,157438 \\
\hline 5. & My Republic & 0,147877 \\
\hline 6. & MNC Play & 0,117257 \\
\hline
\end{tabular}

Tabel 14 menunjukan bahwa alternatif Indihome memiliki skor tertinggi, yaitu sebesar 0,218531 . Alternatif kedua yaitu First Media, diikuti CBN, Biznet Home, MyRepublic dan MNC Play berdasarkan pertimbangan kriteria harga Sistem pendukung keputusan penentuan internet service provider dengan metode Analytical Hierarchy Process (AHP) telah berhasil dibuat. Hasil dalam sistem pendukung keputusan adalah berupa tabel peringkat yang didapat dari perhitungan metode AHP. Setelah melakukan serangkaian pengujian diperoleh hasil alternatif berupa Penentuan Provider Internet Indihome yang merupakan paling ideal untuk digunakan pada jaringan nirkabel di area lingkungan area rumah. Selanjutnya diikuti First Media, CBN, Biznet Home, MyRepublic dan MNC Play berdasarkan kriteria harga bulanan, area 


\section{Jurnal IImu Komputer dan Informatika Vol 2 № 2 \\ p-ISSN: 2776-7418 e-ISSN: 2746-508X}

yang didukung, kecepatan internet, ketersediaan TV kabel dan biaya registrasi menurut sistem pendukung keputusan menggunakan metode AHP.

Pengembangan sistem pendukung keputusan dapat dilakukan untuk menambahkan fitur mencetak laporan dari hasil perhitungan peringkat agar lebih maksimal. Sistem pendukung keputusan dapat dikembangkan dengan mengkombinasikan metode lain seperti simple additive weighting, neuro-fuzzy atau metode lain yang lazim digunakan untuk pengambilan keputusan multikriteria.

\section{DAFTAR PUSTAKA}

[1] W. S. Jatiningrum, S. T. Anwariah, A. P. mahasiswa teknik industri Universitas Ruminda, dan R. P. Tama, "Analytical hierarchy process dalam pemilihan operator seluler untuk paket internet

[2] A. A. Chamid, B. Surarso, dan Farikhin, "Implementasi metode AHP dan promethee untuk pemilihan supplier," Jurnal Sistem Informasi Bisnis, vol. 5, no. 2, Mei, hal. 13-20, 2015.

[3] N. Komalasari, "Sistem Pendukung Keputusan Kelaikan Terbang (SPK2T)," Jurnal Industri Elektro dan Penerbangan, vol. 4, no. 1, 2014.

[4] T. L. Saaty, "Decision making with the analytical hierarchy process," International Journal Services Sciences, vol. 1, no. 1, hal. $83-98,2008$.

[5] M. Bernasconi, C. Choirat, dan R. Seri, "The analytic hierarchy process and the theory of measurement," Management Science, vol. 56, no. 4, hal. $699-711$, 2010.

[6] R. Umar, A. Fadlil, dan Yuminah. "Sistem pendukung keputusan dengan metode AHP untuk penilaian kompetensi soft skill karyawan," Jurnal IImu Komputer dan Informatika, vol. 4, no. 1, hal. $27-34$, 201 